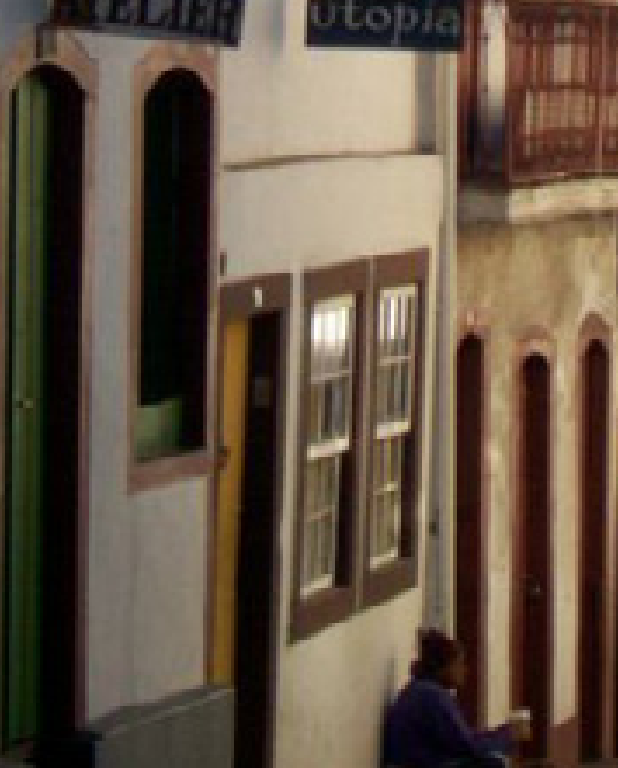
$k_{-4}^{2}$
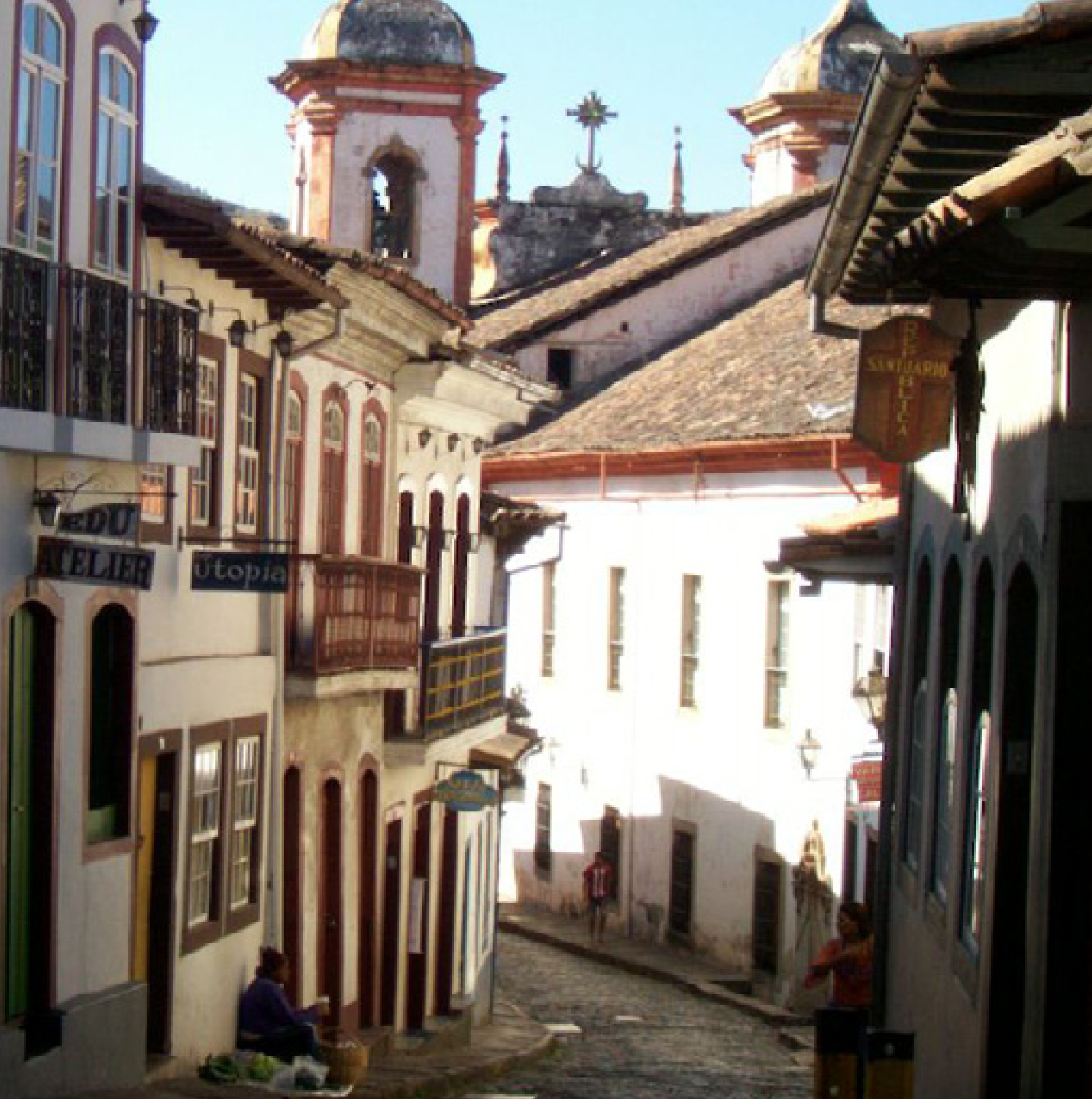


\section{A hospitalidade e a gastronomia no município de Piedade/SP: discutindo possibilidades no âmbito do turismo rural}

The hospitality and gastronomy in Piedade: discussing possibilities within the rural tourism

Ana Cláudia Pádua Machado ${ }^{1}$ Alissandra Nazareth de Carvalho²

1 Bacharel em Turismo pela Universidade Federal de São Carlos, Campus Sorocaba, São Paulo, Brasil. Email: anaclaudiapaduamachado@yahoo.com.br.

2 Doutora em Geografia pela UNESP Rio Claro, Professora Adjunto do Departamento de Turismo, do Centro de Direto, Museologia e Turismo, da Universidade Federal de Ouro Preto/Minas Gerais, Brasil.

Email: alissandracarvalho@yahoo.com.br. 


\section{RESUMO}

O presente artigo discute a proposição de um roteiro gastronômico de Turismo rural no município de Piedade - SP, com foco na hospitalidade. A proposta deste roteiro temático foi desenvolvida a partir da propriedade do Sítio Sakaguti, que recebe um evento anual de Colha e Pague do Caqui Fuyu, com cerca de 8000 visitantes. Para compor tal roteiro, estabeleceu-se uma relação com três outras propriedades rurais, com o intuito de evitar a sazonalidade relativa à produção de caqui fuyu e aumentar a permanência dos turistas no município. Como metodologia, foi realizado trabalho de campo associado à pesquisa qualitativa, com aplicação de questionários semi-estruturados aos gestores familiares das quatro propriedades rurais. Observou-se que a proposição deste roteiro temático de caráter integrado beneficiou as propriedades de maneira equitativa, fomentando o diálogo entre gestão pública, sociedade local, associações de classe e iniciativa privada.

Palavras-chave: Turismo rural. Piedade. Roteiros. Gastronomia. Hospitalidade.

\section{ABSTRACT}

This article discusses the proposition of a gastronomic tour of rural tourism in the municipality of Piedade, focusing on hospitality. The proposition of this thematic tour was developed from a property, called Sítio Sakaguti, that receives every year about 8000 visitors. To compose this tour itinerary, was established a relationship with three other farms, in order to avoid seasonality on the production of Fuyu Persimmon and increase the stay of tourists in the city. As a methodology, a fieldwork was conducted, associated with qualitative research and with application of semi-structured questionary to four farms managers. It was observed that the proposition of this thematic guide benefited the properties equitably by fostering dialogue between public management, local society, associations and private enterprise.

Keywords: Rural Tourism. Piedade. Itineraries. Gastronomy. Hospitality.

\section{INTRODUÇÃO}

O presente trabalho apresenta os resultados, conclusões e considerações obtidos por meio de um projeto de pesquisa vinculado ao grupo de pesquisa do Departamento de Geografia, Turismo e Humanidades, da Universidade Federal de São Carlos, desenvolvido pelas autoras no âmbito da extensão, cujo objetivo se concentrou em propor a formação de um roteiro gastronômico de turismo rural no município de Piedade, interior de São Paulo, uma vez que essa modalidade de turismo se apresenta como uma atividade econômica alternativa, associada à grande potencialidade da referida localidade.

O município de Piedade está localizado a aproximadamente $104 \mathrm{~km}$ da cidade 
de São Paulo e segundo o IBGE (2014), tal município possui uma área total de 747 $\mathrm{km}^{2}$, com $40.17 \mathrm{~km}^{2}$ de área urbana e $688.83 \mathrm{~km}^{2}$ de área rural. Além disso, possui aproximadamente 54.323 habitantes (IBGE, 2014). Segundo as referências do IBGE, percebeu-se que a área de Piedade é em sua maioria rural, além da sua economia ser baseada na atividade agrícola.

Para o historiador Antônio Leite Netto (NETTO, 1987), Piedade desde sua origem foi tida como um celeiro de alimento por suas culturas diversificadas e esse cultivo diverso ocorre atualmente como consequência da crise da cebola na década de 1990 e, parcialmente, pela crise da cenoura, em meados deste mesmo período.

Anteriormente à crise da cebola e a crise da cenoura na década de 1990, a atividade agrícola acontecia em grandes propriedades de monocultura e após este cenário, as grandes propriedades foram segmentadas em pequenas propriedades e a produção mudou, sendo, portanto, diferenciada.

Segundo dados fornecidos pela Diretoria do Departamento Municipal de Turismo (PREFEITURA MUNICIPAL DE PIEDADE, 2013), as principais culturas exercidas na área rural de Piedade são as de morango, alcachofra, caqui, cenoura, batata, cebola, abóbora, batata-doce, beterraba, mandioquinha, tomate, vagem, batatinha, acelga, brócolis, repolho, salsa, alho, chuchu, inhame, mandioca, pepino, pimentão, rabanete, abacate, limão, jiló, couve-flor, manga, maracujá, pêra, tangerina, berinjela, milho, alface, feijão, almeirão, couve e escarola.

Porém, ainda frente a esse cenário de diversificação produtiva na agricultura, essa atividade econômica muitas vezes não é o suficiente para a manutenção de uma boa qualidade de vida familiar para o agricultor, sendo que muitas vezes estes agricultores buscam atividades complementares para incrementar sua renda mensal. Assim, o turismo aparece como uma segunda atividade no próprio território de trabalho, explorando a sua pluriatividade e multifuncionalidade (HATTORI, 2009).

Nesse sentido, o turismo rural aparece como uma alternativa econômica, sendo essa atividade associada a grande potencialidade da localidade, visto suas extensas áreas rurais e diversos atrativos naturais mapeados, além da existência de algumas iniciativas da iniciativa privada, que agradam um crescente número de visitantes.

Dentro desse contexto, o presente trabalho propôs a formação de um roteiro gastronômico de turismo rural no município de Piedade, tomando como ponto de partida a propriedade rural do sítio Sakaguti. A proposta do roteiro englobou quatro atrativos de turismo rural do entorno do Sítio Sakaguti, em um raio de $200 \mathrm{~km}$, contando com este próprio, sendo escolhidos após a realização de um estudo exploratório e 
diálogos com proprietários rurais da área, representantes do poder público e moradores da mesma área, levando em conta suas percepções, considerações e anseios.

A motivação da escolha pelo referido sítio e seu entorno se deu em virtude da ocorrência do evento anual Colha e Pague do Caqui Fuyu, nas propriedades do sítio Sakaguti, nos períodos de março a abril. O evento, que recebeu cerca de 8000 pessoas no ano de 2014, ocorre com a dinâmica da colheita do caqui pelo próprio visitante, que pode degustá-lo no ato ou comprá-lo em quilo. Existe uma área para alimentação de produtos à base do caqui e pratos orientais, com apresentações culturais e espaço para venda de produtos orgânicos. Além disso, existe uma casa-museu, onde são expostos objetos e fotos que contam a história da família Sakaguti.

Com isso, pretendeu-se formatar um roteiro gastronômico de turismo rural nesta região para aumentar o seu fluxo turístico e aumentar as possibilidades dos turistas, que muitas vezes chegam ao município e não possuem ideia do que pode ser explorado. Com o Colha e Pague, associou-se então a Fazenda Kiri, o Sítio Massamitsu e o Sítio Caminho das Orquídeas, com o intuito de diversificar a atividade turística e promover a maior permanência dos turistas, fazendo com que possam frequentar restaurantes locais, equipamentos de comércio turístico e meios de hospedagem.

O trabalho também buscou associar o turismo rural a práticas de hospitalidade e aspectos gastronômicos, já que são essenciais para a ocorrência deste segmento turístico. Por hospitalidade, entende-se que, dentre tantos outros significados e, considerando seu caráter polissêmico, define o bem receber e caracteriza a estadia feliz de um hóspede em uma localidade ou estabelecimento. Associando-o à gastronomia, o rito de sentar-se à mesa representa o estreitamento de laços, possibilidades de interação e ainda, momento de troca não apenas comercial, mas em muito, social (TELFER, 2004; SAVARIN, 2005).

O trabalho justificou-se pela identificação da necessidade da criação de parcerias e associações entre as propriedades, segundo diálogos formais e informais com representantes da gestão pública, proprietários e moradores rurais. Identificou-se uma deficiência na realização de atividades de turismo rural no município, já que há uma carência de auxílio por parte dos representantes públicos, mão-de-obra especializada e a divulgação das mesmas. A apresentação da ideia da criação de roteiros temáticos, incluindo suas propriedades, agradou a todos os proprietários rurais entrevistados, sendo que consideraram um grande avanço para o desenvolvimento da atividade.

A formatação deste roteiro, portanto, possibilitou a formação de parcerias entre proprietários rurais, no sentido de promover a atividade de maneira associada e 
conjunta, fazendo com que o fluxo turístico pudesse ser incrementado. Essa associação também possibilitaria o aumento do fluxo turístico em determinadas propriedades onde ele é diminuto em certas épocas do ano, como é o caso da Fazenda Kiri. Lá, o fluxo turístico diminui entre os meses de março a setembro, e no evento Colha e Pague, o fluxo turístico é muito grande justamente entre março e abril. Assim, ela beneficiaria ambas as propriedades, fazendo com que o turista permaneça mais no município e que frequente possivelmente a Fazenda Kiri.

Assim sendo, identificou-se a possibilidade de explorar com mais propriedade o turismo rural, associado a práticas de preservação do meio natural e ao conhecimento de práticas agrícolas, assim como pôde ser observado nas atividades propostas pelas quatro propriedades colocadas no universo de estudo.

\section{METODOLOGIA}

A pesquisa utilizou a metodologia qualitativa, pois se enquadra na realidade proposta para o trabalho e seu desenvolvimento. Essa escolha ocorreu pois a pesquisa qualitativa trata o objeto de estudo baseando-se na sua relação com o mundo externo, utilizando dos assuntos psicossociais para a interpretação dos fenômenos e a formatação de significados, onde a interpretação, a descrição e a utilização do processo para esse estudo são fundamentais.

Assim, a metodologia qualitativa preocupa-se em "analisar e interpretar aspectos mais profundos, descrevendo a complexidade do comportamento humano e fornece análise mais detalhada sobre as investigações, hábitos, atitudes e tendências de comportamento" (MARCONI e LAKATOS, 2006, p. 269). Essa tipologia de pesquisa é relevante por interpretar os fenômenos e basear-se na observação, adequando-se aos objetivos do trabalho, que visavam o entendimento do universo estudado para posteriores interpretações e demonstrativos de resultados.

Foi realizado um recorte de trabalho a partir do universo, ou seja, o total de agricultores familiares que há em Piedade é de 3.352 agricultores cadastrados até o ano de 2012 , sendo que $75 \%$ são considerados pequenos produtores, com menos de 16 hectares de área (PREFEITURA MUNICIPAL DE PIEDADE, 2013). A partir desse universo, foi obtida uma amostra de estudo e pesquisa, partindo de uma propriedade que representa um polo de atividades turísticas, já previamente identificada e reconhecida pela comunidade de Piedade e também pelo poder público. Trata-se da propriedade dos Fumiko Sakaguti, que realizam todos os anos a festa do Colhe e Pague do Caqui Fuyu, com duração de um mês, alcançando mais de 5.000 visitantes em cada edição. 
A propriedade, através dessa festa, oferece aos visitantes a oportunidade de degustarem o caqui no próprio pé e colherem o produto para consumirem posteriormente. Os produtos consumidos no local são gratuitos e os visitantes pagam somente aquilo que levarem para casa, cujo preço por quilo é de $\mathrm{R} \$ 3,00$. Em um final de semana são colhidas até duas toneladas de caqui pelos turistas.

A justificativa para se ampliar o escopo de possibilidades de visitação do entorno partiu dos próprios visitantes que durante a visitação ao Colha e Pague do Caqui Fuyu sempre perguntam e questionam sobre outras possibilidades aos proprietários e trabalhadores da zona rural. Essa constatação chegou até os canais da prefeitura do município, que por sua vez, procurou a universidade para juntos pensar projetos que desenvolvessem, fomentassem e aprofundassem a atividade turística na região.

Para tanto, todas as propriedades que se encontram no entorno dessa propriedade foram trabalhadas, considerando o turismo de final de semana e o tempo que os turistas teriam para tal atividade. A propriedade do Colhe e Pague foi, portanto, o ponto de partida, para que este turista tivesse a oportunidade de percorrer um trajeto que o fizesse conhecer e ter contato com o entorno da propriedade dos Sakaguti, ampliando suas possibilidades de visitação para o final de semana. Ainda, há que se considerar que o turista pode pernoitar no próprio município ou até mesmo em alguma das propriedades identificadas.

Foi realizada uma pesquisa sistemática junto a prefeitura de Piedade, no setor de agricultura e meio ambiente, onde foi possível obter a informação sobre quais propriedades são familiares, produtivas e quais são os itens produzidos e que por ventura, poderiam vir a se transformar em atrativos para compor roteiros gastronômicos no município.

Durante a pesquisa exploratória, foram ouvidas as famílias e donos das quatro propriedades levantadas, pois uma vez que os proprietários não julgam que seus produtos e localidade não possuem valor para os olhos de outras pessoas, não há como efetuar uma tentativa de desenvolver qualquer atividade nesta propriedade.

Todas as propriedades são geograficamente próximas à propriedade do Sítio Sakaguti, sendo elas: a Fazenda Kiri (com o "Pesca e pague"), a Propriedade Massamistu (com a produção agrícola do morango) e o Sítio Caminho das Orquídeas (com a experiência de conhecimento dos produtos agrícolas, posteriormente consumidos em um café caipira). 


\section{DESCRIÇÃO E APRESENTAÇÃO DAS PROPRIEDADES}

A fazenda Kiri consiste em uma propriedade rural voltada para a psicultura e o entretenimento de visitantes da cidade de Piedade e região, onde são oferecidos alimentos típicos da culinária caipira à base dos variados peixes que são criados em tanques na própria propriedade. Esses peixes podem ser pescados, consumidos no local ou comprados para levar, com o sistema de "pesque e pague". Além disso, a pesca esportiva também é realizada. É localizado no entorno do Sítio Sakaguti, na Estrada da Vila Élvio, no quilômetro 7 e seu horário de funcionamento é de quarta-feira a domingo e feriados, das 8 às 18 horas.

\section{Foto 01: Tanques de pesca da Fazenda Kiri}

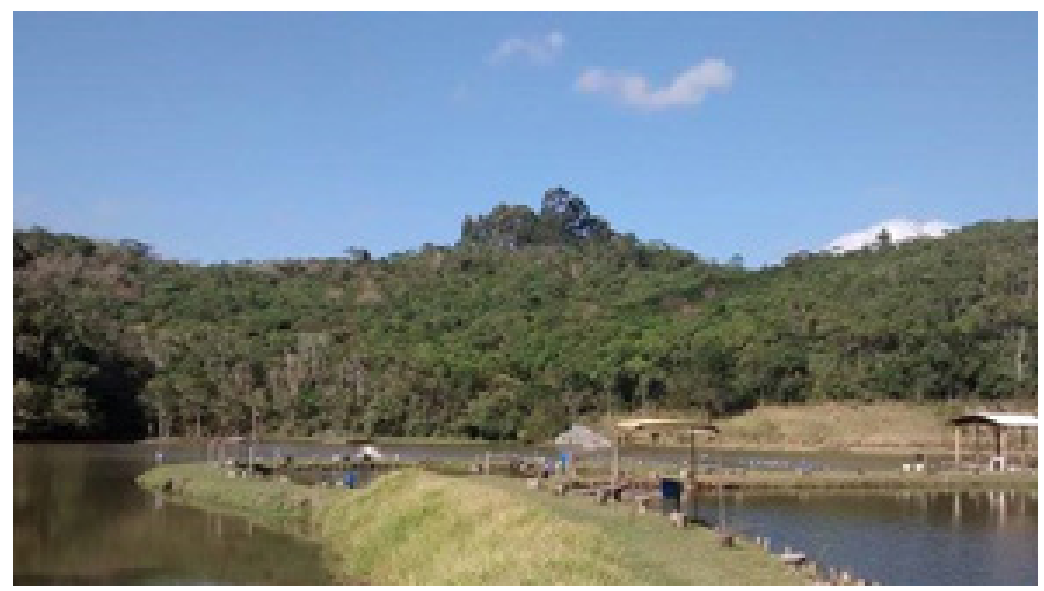

Fonte: a autora (2014).

Foto 02: Barcos e restaurante da Fazenda Kiri

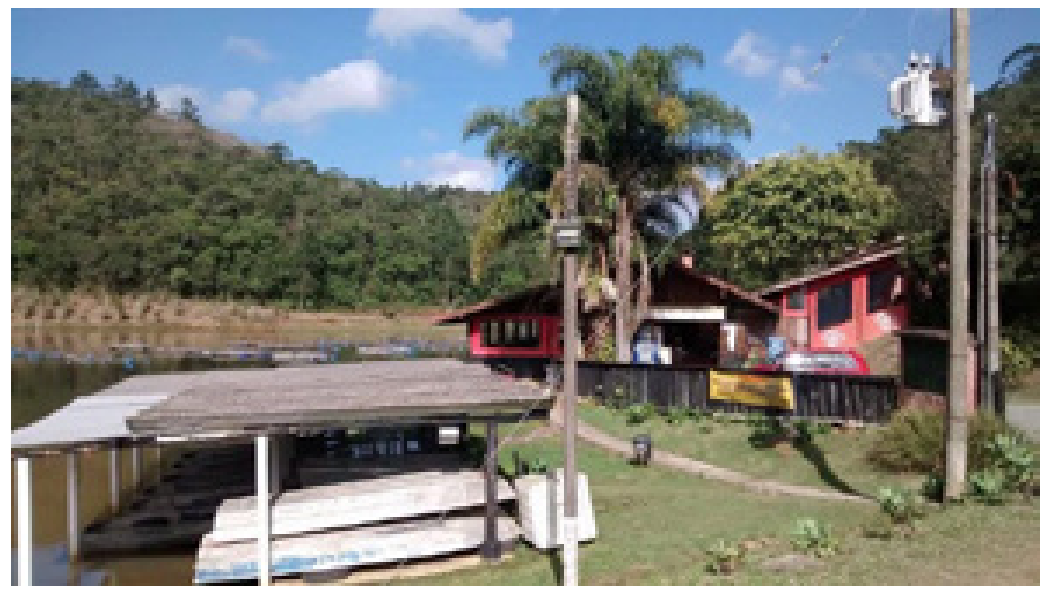

Fonte: a autora (2014). 
O Sítio Caminho das Orquídeas é uma propriedade rural que oferece a experiência de conhecimento de todos os produtos cultivados pela agricultura familiar, que são consumidos posteriormente in loco em um café da manhã tipicamente caipira. Essa atividade só ocorre aos segundos domingos de cada mês, mediante agendamento prévio e é proporcionada pela proprietária do pequeno sítio, com o auxílio de uma funcionária local. Essa mesma proprietária acompanha os visitantes na vivência do cultivo dos produtos, explicando suas percepções e conhecimentos adquiridos pelo cotidiano, como são plantados, cultivados e consumidos, além de explicar a logística de alternância da terra fértil, as dicas de plantação, os insumos utilizados, entre outros aspectos. $O$ custo individual para cada visitante é de quinze reais, e o horário de funcionamento é das 10 às 13 horas.

\section{Foto 03: Material de divulgação do Café Caipira na propriedade Caminho das Orquídeas}

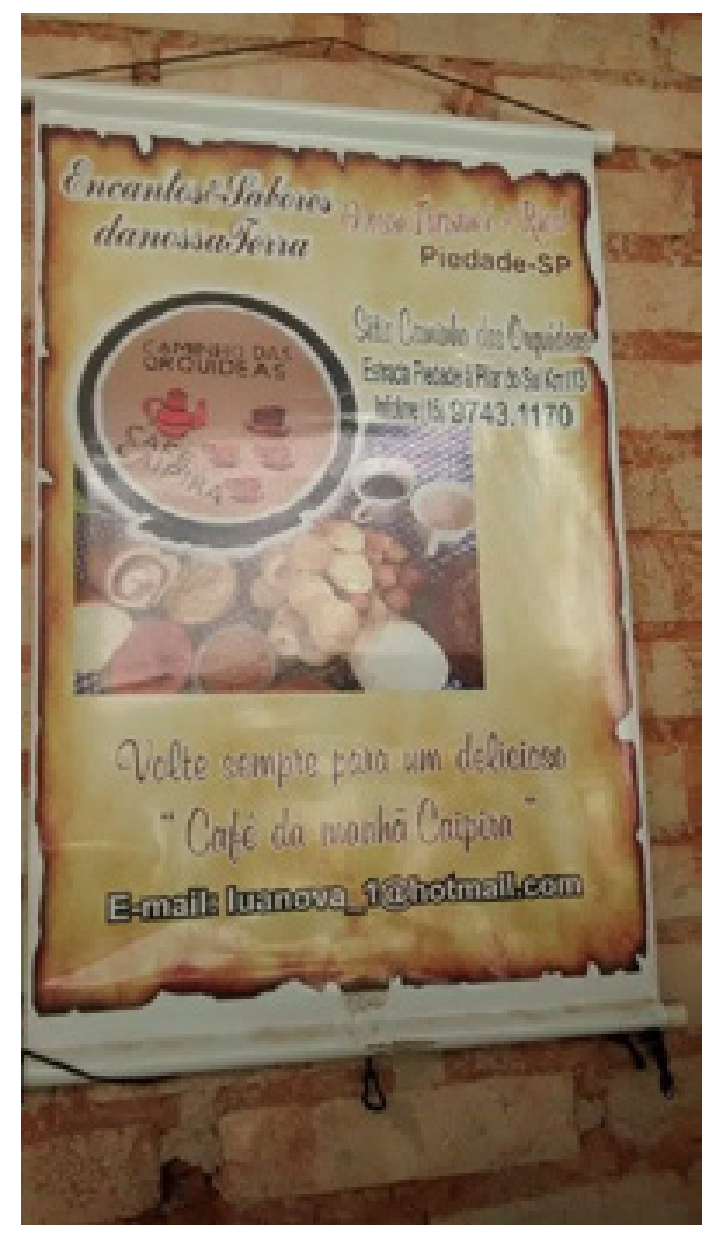

Fonte: a autora (2014). 


\section{Foto 04: Decoração interna no Café Caipira da propriedade Caminho das Orquídeas}

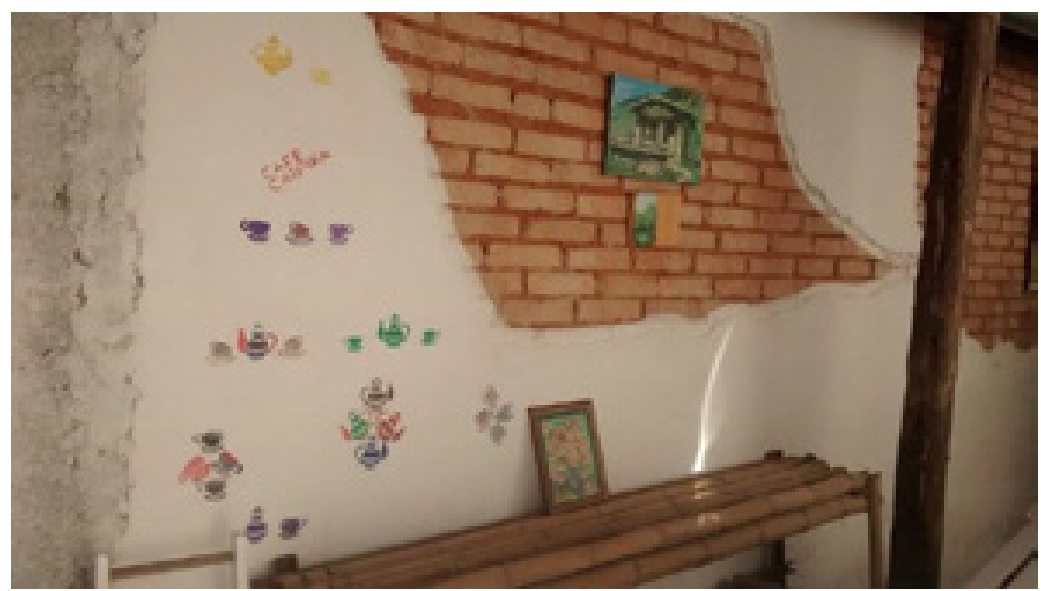

Fonte: a autora (2014).

A propriedade do Sr. Massamitsu, apresenta a área total de 42 hectares, dos quais 2 alqueires são destinados à produção do morango. A área restante da propriedade é destinada à plantação de cenoura, alho porro, caqui e hortaliças. É interessante ressaltar que toda a produção do Sr. Massamitsu é orgânica, sem a utilização de agrotóxicos. A propriedade está situada dentro do maciço da mata Atlântica, apresentando o maior fragmento conservado desse ecossistema.

\section{Foto 05: Plantação de morango do Sítio Massamitsu}

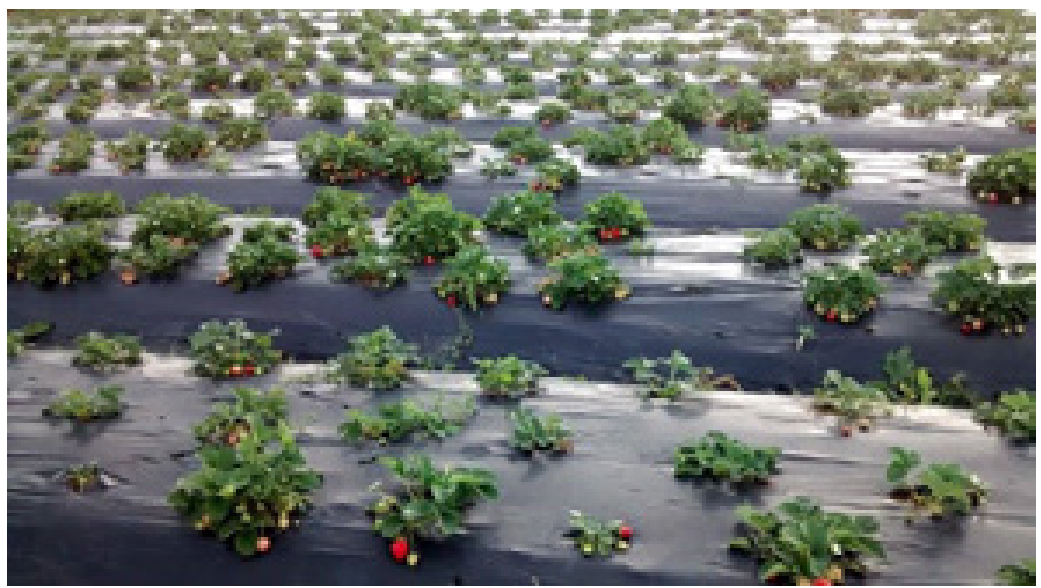

Fonte: a autora (2014) 


\section{Foto 06: Área natural da propriedade do Sítio Massamitsu}

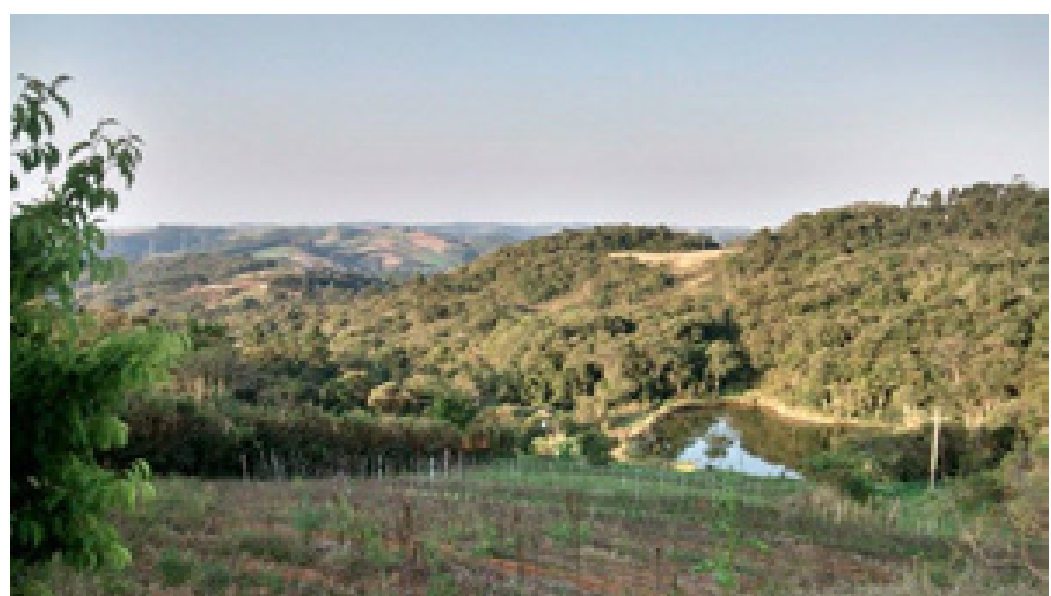

Fonte: a autora (2014).

As propriedades Sítio Sakaguti e Caminho das Orquídeas participam da Associação Amigos do Turismo Rural que é composta por produtores rurais, e visa divulgar a atividade do turismo rural do município de Piedade para outros municípios e turistas em potencial, dentro de feiras e eventos sobre turismo em geral. Além disso, possuem como objetivo a realização da atividade turística entre as propriedades cadastradas de maneira integrada, sendo que cada propriedade complemente a outra.

\section{Foto 07: Colha e Pague Caqui Fuyu 2014}

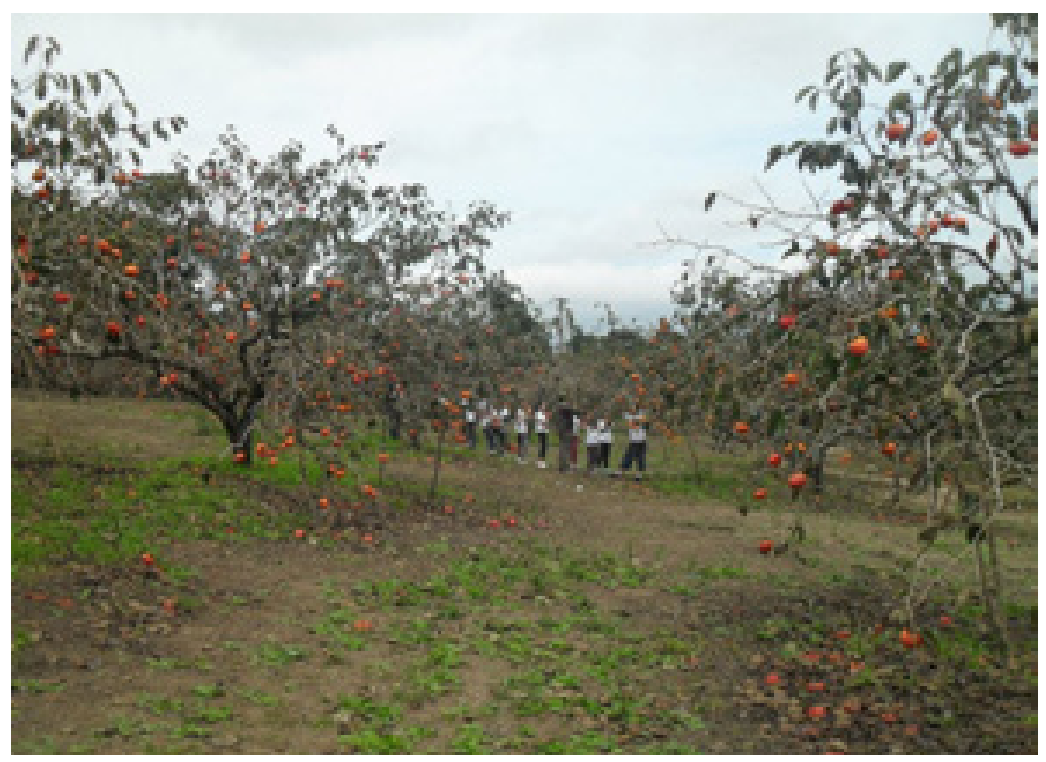

Fonte: Acervo Colha e Pague Piedade (2014). 


\section{ANÁLISE E DISCUSSÃO}

O trabalho de campo exploratório realizado nessas propriedades foi complementado por diálogos realizados com indivíduos relevantes para o estudo, sendo eles um morador local conhecedor das áreas citadas, proprietários de locais que recebem ou pretendem receber atividades de turismo rural e gastronômico, produtores agrícolas, membros da Associação Amigos do Turismo Rural, e representantes do poder público do município.

Foram levantadas questões acerca da definição de turismo rural e turismo gastronômico, levando em conta que alguns autores diferenciam turismo rural de turismo em áreas rurais e alguns não consideram que turismo em áreas naturais é uma definição genérica de atividades em áreas rurais assim como em naturais, sendo o turismo rural um integrante dele, segundo Tulik (2004).

Nesse processo de exploração foi utilizada a técnica de entrevista junto a esses proprietários familiares, cujo roteiro de perguntas composto de questionamentos abertos foi elaborado à luz da literatura pertinente ao turismo rural, roteiros e hospitalidade. As perguntas tiveram um caráter de prospecção e buscaram refinar o instrumento definitivo de coleta de dados, ou seja, o questionário final consolidado que teve o objetivo de identificar o interesse no desenvolvimento da atividade de turismo rural, o conhecimento do que representa a atividade, como lidar com os turistas e suas expectativas, ganhos, incrementos e visibilidade advindos dessa atividade.

As entrevistas foram realizadas durante o terceiro final de semana do evento CoIha e Pague do Caqui Fuyu, momento este intencionalmente e convenientemente escolhido, por estarem todos os proprietários reunidos em uma única oportunidade e também pela possibilidade de se observar a atividade turística acontecendo de forma natural e espontânea.

Nesse momento também aconteceu a sensibilização para a atividade do turismo rural, onde foram desmistificados e rompidos alguns paradigmas a respeito da atividade turística e revelados seus pontos positivos e valorosos.

A posteriori, foram articuladas e cruzadas todas as informações obtidas junto ao poder público, proprietários e documentos consultados, com vistas a futuramente contribuir na elaboração e implementação de um roteiro gastronômico inicial para o município de Piedade.

Nessa primeira visita, no entanto, foi possível identificar que o evento Colha e Pague do Caqui Fuyu, ocorrido na propriedade dos Sakaguti, ocorre em um período limitado, ou seja, do dia 15/03 até o dia 21/04 (de cada ano, com datas levemente 
alteradas, mas sempre nos meses de março e abril). A partir dessa constatação, foi levantada a reflexão acerca da sazonalidade turística, ou seja, se o presente trabalho objetivou sugerir um roteiro gastronômico para o município de Piedade, observou-se que, se o roteiro partisse de um escopo temático, tomando como ponto inicial o sítio Sakaguti para posteriores visitações em propriedades próximas, esse turismo aconteceria somente nesta época do ano, fazendo com que a sazonalidade não seja evitada, mas sim fortalecida.

Para driblar essa sazonalidade, foi necessário se pensar em um desenvolvimento maior deste trabalho de pesquisa e consequentemente na ampliação de seu escopo para a realização de mais de um roteiro de turismo rural e gastronômico, alternando as sugestões de potenciais propriedades identificadas entre os finais de semana, para que a atividade turística ocorra de maneira completa.

Além disso, a questão da sazonalidade turística também é evidenciada pela própria sazonalidade que é fruto do período de colheita do caqui, que acontece somente nos meses de março a abril, sendo que nos meses restantes a propriedade se fecha exclusivamente para a produção da agricultura familiar.

Por isso a necessidade de intercalar essas propriedades citadas nos roteiros propostos, para satisfazer as necessidades dos turistas no período de um final de semana em um mês inteiro e em um ano completo, adicionando outras temáticas agrícolas e gastronômicas ao longo de seus períodos de colheita.

Foi também definido, através do trabalho de campo exploratório realizado e das conversas informais e formais realizadas, o perfil de turistas que o município de Piedade recebe, que consiste em pessoas da melhor-idade, famílias e jovens aventureiros de regiões próximas do município, da grande São Paulo e de outros países, sendo que o Colha e Pague já recebeu cerca de 5.000 turistas e pretende alcançar a meta de 7.000 turistas.

A partir do instrumento de coleta de dados orais, foi possível verificar que as propriedades alavancadas seriam totalmente beneficiadas com a prática do turismo rural de maneira integrada e intercalada, com o intuito de complementação e desenvolvimento. Além disso, a coleta de dados orais possibilitou a conclusão prévia de que essas quatro propriedades deveriam ser os objetos de análise do trabalho de campo, utilizando-se da metodologia da análise do discurso.

Ainda, em posse dessas informações, a prefeitura pode dar continuidade na elaboração de placas de sinalização turística, programas de divulgação sistemáticos via rádio e outdoors na cidade, divulgando também nas outras diversas festas públicas 
que a cidade constantemente está promovendo, para que se faça conhecer a primeira rota gastronômica desenvolvida no entorno de uma das propriedades já previamente reconhecida como relevante em termos de atividades de turismo rural.

\section{PROCEDIMENTO DE CAMPO}

O tratamento dos dados obtidos junto aos entrevistados se deu à luz da metodologia do DSC (discurso do sujeito coletivo) que, segundo Lefévre (2007), se configura em "um discurso síntese elaborado com pedaços de discursos de sentido semelhante reunidos num só discurso", se constituindo em uma técnica qualitativa, na qual é dada a possibilidade de o coletivo falar, a partir da junção dos discursos coletados.

Tendo como fundamento a teoria da Representação Social e seus pressupostos sociológicos, o DSC é uma técnica de tabulação e organização de dados qualitativos que resolve um dos grandes impasses da pesquisa qualitativa na medida em que permite, através de procedimentos sistemáticos e padronizados, agregar depoimentos sem reduzi-los a quantidades (LEFÉVRE, 2007).

Esta metodologia possui quatro elementos que auxiliam na elaboração do discurso final, possibilitando um texto com a junção das ideias do público entrevistado. São essas ferramentas as "expressões-chave", a "ancoragem", "a ideia central”, e o "discurso do sujeito coletivo". Segundo Lefrévre (2007), as "expressões-chave" são trechos, partes do discurso, que garantem a veracidade do mesmo. Já a "ancoragem" consiste na base em que está apoiada o discurso, ou seja, são relatos que os entrevistados utilizam para emoldurar o discurso. A "ideia-central" carrega consigo a função de posicionamento presente nos discursos e revela de maneira substancial o sentido das respostas.

A análise do discurso é uma ferramenta que está diretamente ligada ao significado e ao sentido da mensagem e seu campo de atuação fica entre o campo da linguística e o campo da semântica. Diz respeito a inferência da mensagem por parte do pesquisador, que é carregada de componentes cognitivos, afetivos e valorativos. A mensagem possui representações sociais, opiniões, crenças, expectativas, valores, conceitos, atitudes, entre outros aspectos individuais do objeto de análise, e é ainda recebida da mesma maneira pelo pesquisador que a interpreta de forma particular de acordo com suas crenças, valores, conceitos e opiniões. Assim, "torna-se indispensável considerar que a relação que vincula a emissão das mensagens (que pode ser uma palavra, um texto, um enunciado ou até mesmo um discurso) está, necessariamente, vinculada às condições contextuais de seus produtores." (FRANCO, 2005). 
Pode ser aplicada utilizando a categorização, que consiste na separação dos dados pela diferenciação, seguida pelo reagrupamento por analogias ou temas. Na categorização existe a tática de categorias criadas a priori e as categorias não criadas a priori. Nas categorias criadas a priori, existe a criação de categorias onde as respostas dos objetos de análise se encaixam, contabilizando quantas se encaixam em cada categoria e excluindo as que não se encaixam em alguma categoria. Nas categorias não criadas a priori, não existe a criação de categorias, e as sentenças emergem da fala e do conteúdo da mensagem do objeto de análise, com a descrição do significado e do sentido.

Na aplicação da análise de conteúdo neste presente trabalho, foi utilizada a categorização pelas categorias criadas a priori, pois a categorização cria uma organização das respostas de acordo com suas semelhanças, fazendo com que a sistematização destas seja realizada de maneira mais organizada e facilitada. As respostas dos questionários aplicados foram diferenciadas e reagrupadas pelas semelhanças de temas ou analogias, em categorias. Assim, foram numeradas quais as principais respostas por temas, para se obter um resultado enxuto de quais são as potencialidades e atrativos turísticos deste entorno rural estudado para os proprietários das propriedades rurais ali localizadas.

Os discursos foram gravados e descritos na integra e posteriormente esses discursos foram divididos em categorias de relevância e prioridade, a saber: definição de turismo rural, atrativos potenciais, atrativos elencados, dificuldades e oportunidades.

A partir então da leitura e tratamento de todos os discursos e feitas as devidas comparações, foi elaborado um discurso síntese com a junção de todas as falas dos proprietários/agricultores familiares de Piedade, ou seja, expressões-chave de cada propriedade e as ideias centrais e de maior destaque, onde os entrevistados exprimiram suas opiniões, valores, crenças e ideias sobre a hospitalidade, gastronomia, turismo rural e atividade turística no município.

Esse discurso síntese produzido nos remeteu a identificação de atrativos e potencialidades que podem vir a compor uma devida rota gastronômica para o município.

Após a identificação dos atrativos e potencialidades, os resultados foram sistematizados e traçadas as devidas considerações e conclusões.

\section{RESULTADOS OBTIDOS}

Segundo entrevistas realizadas com a proprietária da Piscicultura Fazenda Kiri, Sra. Marilda Aparecida Traldi, a atividade realizada nesta propriedade é o Pesca e 
Pague, com turistas oriundos de variados municípios, abrangendo um raio de 200 $\mathrm{km}$ de Piedade. A frequência é maior nos finais de semana e entre os meses de março a setembro o movimento é fraco, devido ao clima frio. O público possui demanda diversificada, desde a pesca profissional até a busca da tranquilidade e o sossego que o turismo rural é capaz de proporcionar.

Para a entrevistada, turismo rural "é colocar as pessoas que não tem acesso a tudo o que se tem em uma área rural, como criação de animais, áreas agrícolas e mata, mostrando como se faz o trabalho para saberem como se lida com o produto até ele chegar na mesa". Ela acredita que sua propriedade possui vocação para realização do turismo rural por possuir um caráter empreendedor e pela presença da piscicultura, aliada à estrutura de pesqueiro in-loco. Da mesma forma, Sra. Marilda acredita que a área do entorno à propriedade também possui vocação para o turismo rural, pela presença de áreas verdes (desde que utilizadas de maneira consciente e sustentável), cachoeiras e trilhas.

Considerou como dificuldades para a implantação do turismo rural a falta de divulgação por parte do poder público, a falta de conscientização para com os turistas em relação à preservação da natureza, a falta de manutenção das estradas, que limita o acesso à veículos grandes e de coletivos, e a falta de mão de obra qualificada empenhada em realizar as atividades de manutenção da propriedade em atendimento ao turista.

A entrevistada acredita que a proposição de roteiros gastronômicos de turismo rural na área do entorno de sua propriedade aumentaria o fluxo turístico na localidade, pois identificou uma demanda de turistas que desejam pernoitar no município para a realização de outras atividades.

Em relação as informações coletadas junto a proprietária do sítio Caminho das Orquídeas, Sra. Iracy Godinho, foi possível observar que os turistas interessados pela atividade são em sua maioria oriundos de municípios vizinhos e limítrofes de Piedade, sendo muitos também do município de São Paulo.

Em sua propriedade acontece o evento do Café Caipira, realizado no segundo domingo de cada mês, cuja estimativa de visitantes gira em torno de 300 pessoas ao ano. Segundo a entrevistada, os turistas vislumbram a possibilidade de relaxamento e contato com as raízes rurais, através da experiência gastronômica obtida através de alimentos de origem caipira, além do contato com a natureza. A Sra. Iracy destacou a variedade de pratos tipicamente caipiras oferecidos, além de outros que são particulares da sua família, como o pão de amendoim, receita de sua bisavó vinda da Ucrânia e a paçoca de carne, receita de seu avô, da época do tropeirismo. 
A proprietária definiu o turismo rural como uma forma de oferecer "tudo aquilo que o homem do campo come e produz para o homem da cidade, até mesmo as dificuldades do homem da roça. Isso é turismo rural, você trazer as informações do que acontece no sítio". Dentro do evento Café Caipira, ela leva informações do modo de produção dos pratos e do manejo dos produtos agrícolas, onde há a possibilidade de se observar e participar da colheita, além da compra imediata dos mesmos.

Como empreendedora, Sra. Iracy acredita que possui vocação para o turismo rural por apresentar uma postura profissional na realização do evento, sendo capaz de lidar com eventualidades e imprevistos.

A entrevistada acredita que a área do entorno possui potencialidade turística, e depende da iniciativa privada. Considera a variedade de animais como um grande potencial turístico nessa região, com a possibilidade de realização de birdwatching e observação de bugios e quatis. Como atrativos, ela identificou as cachoeiras e a área verde pela constante busca do turista pela tranquilidade.

Em sua propriedade, a Sra. Iracy acredita que para aumentar o fluxo turístico deve-se melhorar a infraestrutura com o intuito de acolher mais pessoas, implantar um fogão a lenha para caracterizar mais o cenário, e implantar futuramente um acampamento para a pernoite dos turistas.

Para a implantação do turismo na localidade, a entrevistada identificou a falta de mão-de-obra em todos os setores como a maior dificuldade, pois poucas pessoas se dispõem a trabalhar nos finais de semana. A Sra. Iracy não acredita que a divulgação seja uma dificuldade, por possuir apoio público e por conseguir realizá-la por iniciativa própria. Elencou a participação em feiras de turismo, a exemplo do Salão de Turismo, como uma maneira efetiva de divulgação, assim como a participação em eventos municipais.

Vislumbrou-se a realização de roteiros gastronômicos de turismo rural nessas áreas de seu entorno como uma possibilidade de união entre as propriedades e um consequente aumento do fluxo turístico, por possibilitar o aumento da permanência dos turistas na localidade. Elencou como vantagens a presença de público suficiente para todas as propriedades e espaços com a criação dessa parceria, e a possibilidade de um maior conhecimento do município pelos turistas.

A partir do relato da proprietária do Sítio Sakaguti, Sra. Fumiko Sakaguti, identificou-se um grande fluxo turístico oriundo de visitantes principalmente de municípios vizinhos, da grande São Paulo e até de países do exterior. Segundo a Sra. Fumiko Sakaguti, o evento Colha e Pague recebeu cerca de 8000 turistas no ano de 2014. 
Como turismo rural, a proprietária considerou-o como "um lazer de pessoas" onde "as pessoas da cidade vem conhecer e saborear as coisas do rural, para passar o final de semana". A Sra. Fumiku acredita possuir vocação para realizar o turismo rural em sua propriedade pelo fato de já ter cursado o programa anual de turismo rural no Senar e por gostar dessa atividade, além da experiência eficiente do Colha e Pague que já está na sua oitava edição recebendo cada vez mais turistas.

A Sra. Fumiku considerou que existem outras propriedades que representam potencialidades para a realização do turismo rural, identificando a Fazenda Kiri, a Vila Élvio, a Fazenda Canãa (meio de hospedagem associado a esportes radicais) e a Pousada dos Eucaliptos. Identificou como atrativos uma gruta onde fica uma imagem religiosa dentro da Vila Élvio e as áreas verdes e trilhas, onde são realizadas práticas de motocross.

Na sua propriedade, a entrevistada acredita que para aumentar o fluxo turístico deve-se realizar uma maior divulgação e um maior conhecimento do turismo rural, assim como a realização de parcerias com o setor público (sendo que, segundo ela, o evento é eficientemente apoiado pelo Departamento de Turismo do município), aliada a implantação de mecanismos de comunicação turística em toda a cidade. Além disso, a entrevistada vislumbrou melhorias na infraestrutura de recepção dos turistas, mantendo a autenticidade do âmbito rural.

Elencou as mídias eletrônicas e impressas como grandes aliadas para a divulgação do evento Colha e Pague, sendo que várias reportagens foram realizadas e possibilitaram um grande número de novos visitantes.

Dentro da proposta do seguinte projeto, a Sra. Fumiko considerou-a benéfica para um maior conhecimento de Piedade por outros municípios e para a sua inserção na realidade turística do país. Ela identificou os roteiros como vantajosos para os proprietários rurais, tanto para o aumento do fluxo de visitação turística como para uma maior venda de produtos agrícolas.

Por fim, em diálogo realizado com o proprietário do Sítio Massamitsu, foi possível identificar o perfil da propriedade como essencialmente agrícola, com o cultivo de produtos orgânicos. O Sr. Massamitsu identificou a sua propriedade como um grande diferencial na realidade agrícola do município de Piedade, pela presença destes produtos tratados de maneira diferenciada, sendo cada vez mais visados pelos consumidores do município e região, além da grande São Paulo. Dentro de seus produtos cultivados, estão a cenoura, a beterraba e o morango, sendo que o cultivo deste último é visitado por grupos previamente agendados. Informou que produz e vende $1000 \mathrm{~kg}$ de cenoura e $400 \mathrm{~kg}$ de beterraba semanalmente. 
O entrevistado acredita que turismo rural é uma atividade "para as pessoas da cidade que querem conhecer as novidades do sítio, que não são novidades para as pessoas da roça".

Não soube responder se possui vocação para o turismo rural, já que não realiza visitas periódicas na sua propriedade, mas demonstrou um interesse na implantação das mesmas, já que a atividade do turismo rural representa uma nova possibilidade para a multifuncionalidade e pluriatividade das propriedades, assim como deseja apresentar seus produtos orgânicos para um maior número de pessoas.

O Sr. Massamistu considerou a área do entorno de sua propriedade como potencial para a realização do turismo rural, já que se localiza próximo a Vila Élvio (com enfoque na sua conservação histórica) e também à propriedade onde é realizado o Colha e Pague do Caqui, além de estar cercado por áreas verdes que são exploradas pela realização do motocross e do cicloturismo. Segundo ele, são muitas as pessoas que praticam o cicloturismo, oriundos de variados municípios.

O entrevistado considerou a divulgação pelo âmbito público uma das necessidades para o aumento do fluxo turístico na região, assim como melhorias na infraestrutura para o recebimento eficiente dos turistas.

Como dificuldades na implantação da atividade turística, o Sr. Massamistu destacou a falta de infraestrutura para receber os turistas e a falta de mão de obra para a realização de tarefas diárias relacionadas a recepção dos turistas de maneira profissional. Foi considerada a implantação de uma proposta do trabalho como um instrumento de divulgação da propriedade frente ao município, aliado ao desejo de fomentar a atividade de turismo rural no local, buscando aumentar as possibilidades plurais e também a permanência dos visitantes na localidade.

\section{CONSIDERAÇÕES FINAIS}

O trabalho proposto foi providencial à reflexão da atividade do turismo rural, aliada a gastronomia e hospitalidade, realizada de maneira integrada, se comportando como beneficiadora social, econômica, cultural e ambiental no município de Piedade.

Foi possível identificar as potencialidades existentes neste território e vislumbrar atividades que possam ser realizadas de maneira sustentável nesse território. Além disso, foi possível identificar as propriedades agrícolas que já realizam atividades turísticas e aquelas que vislumbram esta ação no futuro, auxiliando para a concretização efetiva desta ideia. 
Como discurso síntese que pôde ser elaborado a partir da fala dos entrevistados, à guisa de conclusão, tem-se que como definição de turismo rural, todos os entrevistados chegaram em uma resposta que considerava a relação do turista com a natureza, com a tranquilidade e com as áreas naturais, sendo foco principalmente de pessoas oriundas da grande cidade de São Paulo.

Quanto as dificuldades obtidas para a implantação do turismo rural em suas propriedades, a resposta dos entrevistados foi unânime, ou seja, ressaltou-se a falta de mão-de-obra local para a implementação e manutenção da atividade, assim como a recepção dos turistas. Associada a falta de mão-de-obra, foi elencada também a falta de qualificação profissional da mão-de-obra existente e necessária. Também foi elencada a falta de divulgação do município e dos atrativos por parte da gestão pública e também dos próprios entrevistados (por falta de recursos) e a falta de infraestrutura adequada nas estradas para o recebimento dos turistas.

Para a questão dos atrativos e potencialidades notadas no entorno, a Vila Élvio foi majoritariamente citada, sendo seguida pela Fazenda Eco Canãa e a Pousada dos Eucaliptos. Como potencialidades foram identificadas a Cachoeira do Alemão, a Cachoeira da Fumaça e a área de mata nativa localizada na Vila Élvio.

Em geral, demonstrou-se que os entrevistados se preocupam com a infraestrutura adequada para o recebimento de turistas assim como a prática da hospitalidade, mas reconhecem que se deve manter muitos aspectos originais para uma prática turística autêntica. Além disso, a apresentação da proposta deste trabalho, da formatação de um roteiro integrado gastronômico de turismo rural, foi muito bem vista por todos os proprietários, que vislumbraram a oportunidade de aumentar seu fluxo turístico, realizar uma maior integração com outros produtores rurais e divulgar com uma maior visibilidade suas propriedades. Todos consideraram a proposta benéfica para eles próprios, para outras propriedades rurais, para o âmbito público e para a atividade turística no município em geral.

Com isso, o projeto foi beneficiador no aspecto social, tanto para o lado da atividade turística quanto para os proprietários agrícolas, no sentido de proporcionar uma segunda atividade econômica que complemente suas rendas familiares, explorando a pluriatividade e a multifuncionalidade de suas propriedades.

Através da realização deste trabalho, concluiu-se também que a roteirização deve ser realizada sempre aliada ao planejamento turístico, para ser implantada de maneira efetiva. Alguns exemplos de falta de planejamento foram demonstrados em algumas localidades do município, que muitas vezes não possuem infraestrutura adequada para receber os turistas de maneira eficiente e sustentável. 
Além disso, o planejamento para a formatação de roteiros possibilita o levantamento de potencialidades e a união de propriedades, formatando atividades de maneira integrada e assim mais fortificada.

O trabalho contribuiu para a academia aumentando o número de pesquisas e reflexões na área do turismo, estimulando pesquisas com mais qualidade e aumentando o horizonte de análise do turismo, associando a teoria à prática e apoiando o processo de tomada de decisões da gestão pública em Piedade. Também, dentro deste contexto, foi possível a criação de algumas diretrizes para o processo de planejamento e roteirização das áreas rurais de Piedade, sendo que isso ainda não era realizado de maneira contínua e associada, mas em ações isoladas e descontínuas.

Para o município, o trabalho representou ideias para o seu desenvolvimento turístico, que foi identificado como um dos principais objetivos da atual gestão pública. Observou-se que a mesma gestão enxergava a atividade turística como algo exclusivamente econômico e o trabalho pôde vislumbrar a proposta de roteirização e planejamento turístico associado essencialmente com a qualidade da oferta turística, além dos essenciais elementos de informação e comunicação turística, para que finalmente seja possível fomentar a economia de uma maneira eficiente e sustentável.

Dentro da questão da sua prática sustentável, levou-se em conta não só a sustentabilidade ambiental, mas também a social, cultural, entre outras. Fez-se então com que a roteirização apresentasse a sustentabilidade como um veículo de benefícios mútuos, tanto para os empreendedores da atividade turística como para os turistas, além dos moradores locais e dos gestores públicos e privados.

Como sugestões para futuros trabalhos, propõe-se a realização de um trabalho de campo associado a coleta de dados nessas propriedades alavancadas, formatando roteiros completos que possam contemplar as questões gastronômicas da alcachofra em determinada época do ano, morango em outra época do ano e a Festa do Caqui-Fuyu que ocorre anualmente, durante três dias no mês de maio, entre outras. Sugere-se também opções de meios de hospedagem, pontos de alimentação (como o Restaurante Estação Boca do Monte), equipamentos de entretenimento que complementariam o produto turístico oferecido, entre outras possibilidades. 


\section{REFERÊNCIAS BIBLIOGRÁFICAS}

FRANCO, Maria Laura P. Barbosa. Análise de Conteúdo. Brasília: Plano Editora, 2003 HATTORI, Eduardo Takeshi. Arranjos Produtivos Locais como estratégia de planejamento do Turismo Rural: Proposta de criação de um APL de Turismo em Piedade-SP. Trabalho de conclusão de curso, Bacharelado em Turismo, UFScar Campus Sorocaba, Sorocaba, 2009.

IBGE Cidades. Disponível em:<http://www.cidades.ibge.gov.br>. Acesso em 31 maio. 2014.

LEFEVRE, Fernando. Disponível em < http://www.fsp.usp.br/ flefevre/Discurso_ sujeito_coletivo.htm>. Acesso em 06 de maio de 2013.

MARCONI, M. A.; LAKATOS, E. M. Metodologia científica. 4. ed. São Paulo: Atlas, 2006.

NETTO. Leite, Antônio. História de Piedade. Piedade, São Paulo: CULTURESP LTDA, 1987.

PREFEITURA MUNICIPAL DE PIEDADE. Disponível em <http://www.piedade.sp.gov. br/> Acesso em 06 de maio de 2013.

SAVARIN, Brillat. A Fisiologia do Gosto. São Paulo: Companhia das Letras, 2005.

TELFER, Elizabeth. A filosofia da “hospitabilidade". In: MORRISON, Alison; LASHLEY, Conrad. Em busca da hospitalidade. São Paulo: Manole, 2004.

TULIK, Olga. Turismo Rural. São Paulo: Aleph, 2003. 